\title{
ROS Production Is Increased in the Kidney but Not in the Brain of Dahl Rats With Salt Hypertension Elicited in Adulthood
}

\author{
M. VOKURKOVÁ ${ }^{1}$, H. RAUCHOVÁ ${ }^{1}$, L. ŘEZÁČOVÁ ${ }^{1}$, I. VANĚČKOVÁ $^{1}$, J. ZICHA $^{1}$ \\ ${ }^{1}$ Institute of Physiology, Czech Academy of Sciences, Prague, Czech Republic
}

Received April 13, 2014

Accepted May 15, 2015

\begin{abstract}
Summary
Enhanced production of superoxide radicals by nicotinamideadenine dinucleotide phosphate (NADPH) oxidase in the brain and/or kidney of salt hypertensive Dahl rats has been proposed to participate in the pathogenesis of this form of experimental hypertension. Most information was obtained in young Dahl saltsensitive (DS) rats subjected to high salt intake prior to sexual maturation. Therefore, the aim of our study was to investigate whether salt hypertension induced in adult DS rats is also accompanied with a more pronounced oxidative stress in the brain or kidney as compared to Dahl salt-resistant (DR) controls. NADPH oxidase activity as well as the content of thiobarbituric acid-reactive substances (TBARS) and conjugated dienes (oxidative index), which indicate a degree of lipid peroxidation, were evaluated in two brain regions (containing either hypothalamic paraventricular nucleus or rostral ventrolateral medulla) as well as in renal medulla and cortex. High salt intake induced hypertension in DS rats but did not modify blood pressure in DR rats. DS and DR rats did not differ in NADPH oxidase-dependent production of ROS, TBARS content or oxidative index in either part of the brain. In addition, high-salt diet did not change significantly any of these brain parameters. In contrast, the enhanced NADPH oxidase-mediated ROS production (without significant signs of increased lipid peroxidation) was detected in the renal medulla of salt hypertensive DS rats. Our findings suggest that there are no signs of enhanced oxidative stress in the brain of adult Dahl rats with salt hypertension induced in adulthood.
\end{abstract}

\section{Key words}

Dahl rats - Lipid peroxidation - Nicotinamide-adenine dinucleotide phosphate (NADPH) oxidase - Reactive oxygen species $\bullet$ Salt hypertension

\section{Corresponding author}

H. Rauchová, Institute of Physiology, Czech Academy of Sciences, Videnska 1083, 14220 Prague 4, Czech Republic. Fax: +420 24106 2488. E-mail: rauchova@biomed.cas.cz

\section{Introduction}

Rather complex blood pressure (BP) regulation is still not completely elucidated. The brain plays an essential role in the control of arterial BP and there is considerable evidence that hypertension in both humans and animal models has a neurogenic basis. There are two major centers of BP control - the hypothalamic paraventricular nucleus (PVN) and the rostral ventrolateral medulla (RVLM) (Guyenet 2006). Recently, much attention has been paid to the role of altered central $\mathrm{BP}$ regulation in the pathogenesis of hypertension (Hirooka 2011, Gabor and Leenen 2012).

Oxidative stress is generally accepted as one of the important mechanisms responsible for the development of human and/or experimental hypertension (Parik et al. 1996, Manning et al. 2005). Oxidative stress arises from the imbalance between excessive reactive oxygen species (ROS) generation, reduced nitric oxide (NO) levels and decreased bioavailability of antioxidants (Rodrigo et al. 2011, Baradaran et al. 2014). Plasma membrane nicotinamide adenine dinucleotide phosphate (NADPH) oxidase is well known as a significant producer of superoxide radicals $\left(\mathrm{O}_{2}^{-}\right)$. Its activation can remarkably contribute to the oxidative stress (Lassègue and Griendling 2004).

Similarly to the human population, the rats can also show varying degree of resistance to BP elevating effects of high salt intake. The excess salt ingestion is 
regarded as one of major factors in the pathogenesis of hypertension. The most widely used genetic model of salt hypertension is Dahl rats (for review see Zicha et al. 2012a). More than 50 years ago, Dahl et al. (1962) selected two contrasting substrains of Sprague-Dawley rats differing substantially in BP elevation when fed a high-salt diet (Dahl salt-sensitive rats, DS and Dahl salt-resistant rats, DR). A considerable attention was paid to the formation and the role of ROS in Dahl rats. Indeed, the increased oxidative stress was observed in salt hypertensive Dahl rats (Swei et al. 1997, Meng et al. 2003, Taylor and Cowley 2005), and the attenuation of salt hypertension development by various antioxidant interventions was also reported in this model of experimental hypertension (Swei et al. 1999, Forde et al. 2003, Nishiyama et al. 2004, Zhang et al. 2004). Enhanced ROS production was detected in various organs of salt hypertensive Dahl rats including kidney (Trolliet et al. 2001, Forde et al. 2003), heart (Tsutsui et al. 2001, Tojo et al. 2002, Guo et al. 2006) and blood vessels (Swei et al. 1997, Bayorh et al. 2004). Much less is known about ROS formation in the brain of salt hypertensive animals, although Fujita et al. (2007) demonstrated that sympathoexcitation and salt hypertension in young Dahl rats is related to their enhanced hypothalamic production of ROS by NADPH oxidase.

Our earlier studies demonstrated the enhanced BP fall after acute intravenous injection of tempol (superoxide dismutase mimetic) in salt hypertensive Dahl rats, the effect being greater in young than in adult animals (Zicha et al. 2001, Dobešová et al. 2002). Later, we have disclosed a more pronounced increase of oxidative stress in adult salt hypertensive Dahl rats in which a positive correlation between BP and ROS production in thoracic aorta or kidney was observed (Vaněčková et al. 2013). We have also found that chronic oral tempol administration attenuated salt hypertension development only in adult Dahl rats but not in young ones. This BP reduction was mediated by a reduction in sympathetic vasoconstriction (Vaněčková et al. 2013). The differences in the pathogenetic mechanisms of salt hypertension elicited in immature or adult rats are wellknown (for review see Zicha et al. 1986, Zicha and Kuneš 1999) but our knowledge on the age-dependent involvement of oxidative stress is still limited. This was a reason why we decided to study the oxidative stress in both brain and kidney of salt-sensitive (DS) and saltresistant (DR) Dahl rats subjected to high salt intake in adulthood.

The aim of the present study was to investigate i) whether salt hypertension is accompanied by a more pronounced oxidative stress in two brain regions which contain either PVN or RVLM, ii) whether DS and DR rats differ in ROS production by NADPH oxidase in the brain, and iii) whether these parameters of oxidative stress are altered in renal medulla or renal cortex of the same animals.

\section{Material and Methods}

\section{Reagents}

Nicotinamide-adenine dinucleotide phosphate (NADPH), ethylene glycol-bis(2-amino-ethylether)N,N,N',N'-tetraacetic acid (EGTA), aprotinin, leupeptin, pepstatin, phenylmethylsulfonyl fluoride, 1,1,3,3tetraethoxypropane, lucigenin and Folin reagent were purchased from Sigma-Aldrich Co (USA), Lubrol from Serva (Germany). All other reagents were of the purest grade commercially available.

Animals

Five-month-old male inbred Dahl/Rapp saltsensitive (DS) and salt-resistant (DR) rats from the breeding colony of the Institute of Physiology CAS (Prague) were used for our experiments. The animals were housed under standard laboratory conditions (temperature $23 \pm 1{ }^{\circ} \mathrm{C}, \quad 12-\mathrm{h}$ light/dark cycle) and maintained on tap water and standard rodent chow ad libitum. From the age of 3 months the rats of both genotypes were fed either a low-salt (LS, $0.3 \% \mathrm{NaCl}$ ) or a high-salt (HS, $5.0 \% \mathrm{NaCl}$ ) diet for 2 months. All procedures and experimental protocols in the experimental animals, which were approved by the Ethical Committee of the Institute of Physiology CAS, conform to the European Convention on Animal Protection and Guidelines on Research Animal Use.

\section{Measuring of systolic blood pressure}

Systolic blood pressure (SBP) was measured by tail cuff method always between 8:00 and 10:00 a.m.

\section{Sample preparation}

At the end of the experiment, the animals were euthanized by decapitation in ether anesthesia. The hearts were removed and weighted. The kidneys were removed, weighted and divided on medulla and cortex. The brains were removed from the scull on ice-cold platform. The 
macroscopic structures of the brainstem (without cerebellum) were manually separated in two parts according to a rat brain atlas (Paxinos and Watson 2005): Part A: diencephalon including PVN (AP 0 to AP -5) and part B: medulla oblongata + pons including RVLM (AP -9 to AP -15). The mean weights of the individual blocks of brain tissue $( \pm$ SEM) were $198 \pm 6$ and $152 \pm 3 \mathrm{mg}$ for parts A and B, respectively. The dissected parts of the brain and renal medulla and cortex were homogenized in $10 \%$ (wt/vol) ice-cold lysis buffer containing $20 \mathrm{mmol} / \mathrm{l}$ $\mathrm{KH}_{2} \mathrm{PO}_{4}, 1 \mathrm{mmol} / 1$ EGTA, $1 \mu \mathrm{g} / \mathrm{ml}$ aprotinin, $1 \mu \mathrm{g} / \mathrm{ml}$ leupeptin, $1 \mu \mathrm{g} / \mathrm{ml}$ pepstatin, $1 \mathrm{mmol} / 1$ phenylmethylsulfonyl fluoride ( $\mathrm{pH}$ 7.4). Homogenates were filtered through two layers of gauze on ice and used for further analyses. Folin method was used for the determination of protein concentration in the homogenates using bovine serum albumin as standard (Lowry et al. 1951).

\section{Measurement of NADPH oxidase activity}

The lucigenin-enhanced chemiluminescence assay was used to determine NADPH oxidase-mediated superoxide radical $\left(\mathrm{O}_{2}^{-}\right)$production in the brain and renal medulla and cortex homogenates (Matsui et al. 2006). The reaction was started by the addition of NADPH $(0.1 \mathrm{mmol} / \mathrm{l})$ to the suspension $(250 \mu \mathrm{l}$ final volume $)$ containing assay phosphate buffer $\left(50 \mathrm{mmol} / 1 \mathrm{KH}_{2} \mathrm{PO}_{4}\right.$, $1 \mathrm{mmol} / 1$ EGTA, $150 \mathrm{mmol} / 1$ sucrose, $\mathrm{pH} \mathrm{7.4),} \mathrm{sample}$ and lucigenin $(5 \mu \mathrm{mol} / \mathrm{l})$. The luminescence was measured at $30{ }^{\circ} \mathrm{C}$ every $5 \mathrm{~s}$ for 10 min using Tecan Infinite M200 multimode microplate fluorometer. Buffer blank was subtracted from each reading. The activity of NADPH oxidase is expressed as counts per mg protein.

\section{Measurement of lipid peroxidation}

Lipid peroxidation in the samples was monitored by measuring thiobarbituric acid-reactive substances (TBARS) formation (Ohkawa et al. 1979). To determine TBARS, the brain homogenates were incubated with thiobarbituric and acetic acid at $95{ }^{\circ} \mathrm{C}$ for $45 \mathrm{~min}$. After cooling the developed fluorescent substance was extracted with n-butanol. Fluorescence of the organic phase was measured at an excitation wavelength of $515 \mathrm{~nm}$ and an emission wavelength of $553 \mathrm{~nm}$ using Tecan Infinite M200 multimode microplate fluorometer. A calibration curve was prepared from 1,1,3,3tetraethoxypropane. The results were expressed as nmol of TBARS per mg of protein.

\section{Determination of conjugated dienes}

Samples of brain and kidney homogenates $(0.020 \mathrm{mg}$ of protein) were added to $1 \mathrm{ml}$ of $10 \mathrm{mmol} / 1$ phosphate buffer ( $\mathrm{pH} 7.4$ ) with $1 \%$ (wt/vol) Lubrol. Formation of conjugated dienes was measured from the absorbance ratio $\mathrm{A}_{233} / \mathrm{A}_{215}$ (oxidative index) using a spectrophotometer Beckman DU-7 (Klein 1970, Kaplán et al. 2000).

\section{Determination of thiol concentrations}

The intracellular content of reduced glutathione (GSH) in renal cortex, heart and liver was determined according to the method described earlier (Ellman 1959). Briefly, the tissue samples were homogenized in $3 \%$ sulfosalicylic acid and $10 \%$ homogenates were centrifuged for $10 \mathrm{~min}$ at $3000 \mathrm{~g}$. A portion of the supernatant was mixed with $0.02 \mathrm{M}$ 5,5'-dithiobis-(2nitrobenzoic acid) in $0.1 \mathrm{M}$ phosphate buffer $(\mathrm{pH} 8)$ and the absorbance of a colored product was read on a spectrophotometer at $412 \mathrm{~nm}$. The concentration of GSH was calculated from a calibration curve prepared by serial dilution of $1 \mathrm{mM}$ stock solution. The results were expressed as $\mu \mathrm{mol} \mathrm{GSH} / \mathrm{g}$ tissue.

\section{Statistical analysis}

Results are expressed as mean \pm SEM and the statistical differences among experimental groups were evaluated by two-way analysis of variance (ANOVA) followed by Bonferroni post-test with factors salt intake (low and high) and genotype (DR and DS). The ANOVA was performed with GraphPad Prism software. A value of $\mathrm{P}<0.05$ was considered to be statistically significant.

\section{Results}

Initial values of systolic blood pressure, which were recorded prior to the experiment under the conditions of low salt intake $(0.3 \% \mathrm{NaCl}$ diet $)$, were similar in DS and DR rats aged 3 months (Table 1). At the end of the experiment higher SBP was found in DS rats compared to DR rats fed a low-salt diet, but these two groups did not differ in relative heart or kidney weights. On the other hand, two-month feeding with high-salt diet $(5 \% \mathrm{NaCl})$ induced hypertension and increased relative heart and kidney weights in DS rats without significant changes in DR rats. Higher concentrations of thiols were found in heart, renal cortex and liver of DS rats compared to DR ones irrespective of their salt intake (Tables 1 and 2). 
Table 1. Systolic blood pressure (SBP), body weight (BW), relative heart weight (HW/BW), relative kidney weight (KW/BW) and thiols (SH) concentration in heart, kidney cortex and liver in salt-resistant (DR) and salt-sensitive (DS) Dahl rats fed either low-salt (LS, $0.3 \%$ $\mathrm{NaCl}$ ) or high-salt ( $\mathrm{HS}, 5.0 \% \mathrm{NaCl}$ ) diet for 2 months from the age of 3 months.

\begin{tabular}{|c|c|c|c|c|}
\hline & DR/LS & DR/HS & DS/LS & DS/HS \\
\hline Number of rats & 7 & 6 & 6 & 5 \\
\hline Initial SBP (mm Hg) & & $137 \pm 4$ & & $144 \pm 6$ \\
\hline Final SBP (mm Hg) & $136 \pm 4$ & $139 \pm 2$ & $162 \pm 4 *$ & $213 \pm 5 * \#$ \\
\hline$B W(g)$ & $347 \pm 6$ & $391 \pm 8^{\#}$ & $426 \pm 9 *$ & $408 \pm 11$ \\
\hline$H W / B W(m g / g)$ & $2.76 \pm 0.04$ & $2.78 \pm 0.05$ & $2.69 \pm 0.03$ & $3.20 \pm 0.07 * \#$ \\
\hline$K W / B W(m g / g)$ & $6.16 \pm 0.13$ & $6.87 \pm 0.21$ & $5.75 \pm 0.16$ & $7.82 \pm 0.26 * \#$ \\
\hline SH heart $(\mu \mathrm{mol} / \mathrm{g})$ & $2.10 \pm 0.23$ & $1.93 \pm 0.14$ & $2.68 \pm 0.30 *$ & $2.73 \pm 0.23 *$ \\
\hline SH kidney ( $\mu \mathrm{mol} / \mathrm{g})$ & $4.25 \pm 0.17$ & $3.99 \pm 0.20$ & $4.74 \pm 0.24 *$ & $4.65 \pm 0.27 *$ \\
\hline SH liver $(\mu \mathrm{mol} / \mathrm{g})$ & $6.39 \pm 0.57$ & $6.62 \pm 0.64$ & $10.1 \pm 0.66^{*}$ & $10.8 \pm 1.27 *$ \\
\hline
\end{tabular}

Data are means \pm SEM. Significantly different: ${ }^{*} \mathrm{P}<0.05$ from DR strain on the same diet; ${ }^{*} \mathrm{P}<0.05$ from the rats of the same genotype fed LS diet.

Table 2. Two-way ANOVA analysis of the data from Table 1.

\begin{tabular}{|c|c|c|c|c|c|c|}
\hline \multirow[t]{2}{*}{ Effect of } & \multicolumn{2}{|c|}{ salt intake } & \multicolumn{2}{|c|}{ genotype } & \multicolumn{2}{|c|}{ interaction } \\
\hline & $\mathbf{F}_{1,20}$ & $\mathbf{P}<$ & $\mathbf{F}_{1,20}$ & $\mathbf{P}<$ & $\mathbf{F}_{1,20}$ & $\mathbf{P}<$ \\
\hline Final SBP (mm Hg) & 39.26 & 0.001 & 136.8 & 0.001 & 31.04 & 0.001 \\
\hline$B W(g)$ & 2.203 & NS & 27.96 & 0.001 & 12.06 & 0.01 \\
\hline$H W / B W(m g / g)$ & 25.16 & 0.001 & 11.29 & 0.01 & 21.15 & 0.001 \\
\hline$K W / B W(m g / g)$ & 46.15 & 0.001 & 1.762 & NS & 10.99 & 0.01 \\
\hline SH heart ( $\mu \mathrm{mol} / \mathrm{g})$ & 0.290 & NS & 38.35 & 0.001 & 0.880 & NS \\
\hline SH kidney ( $\mu \mathrm{mol} / \mathrm{g})$ & 2.530 & NS & 27.55 & 0.001 & 0.560 & NS \\
\hline SH liver $(\mu \mathrm{mol} / \mathrm{g})$ & 1.590 & NS & 104.0 & 0.001 & 0.470 & NS \\
\hline
\end{tabular}

NS - no significant difference. For other abbreviations see Table 1.
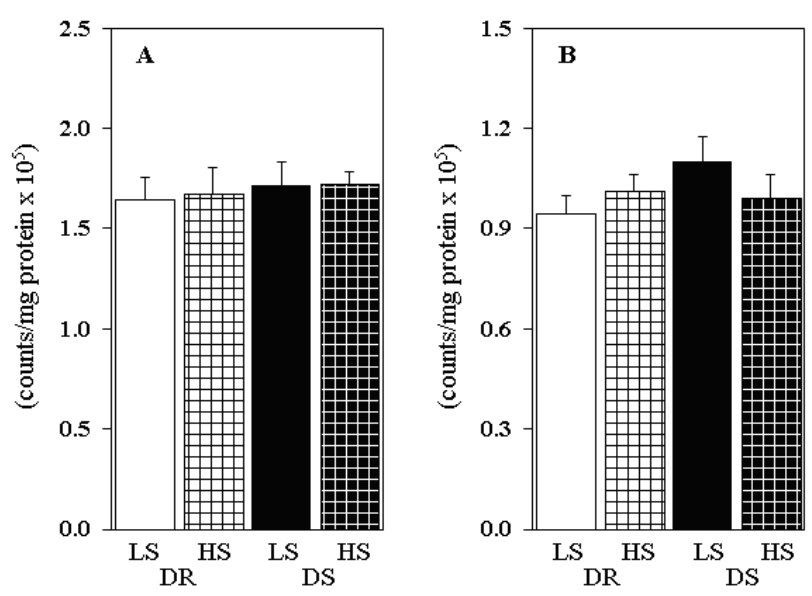

Fig. 1. NADPH oxidase-mediated ROS production in the diencephalon (A) and medulla oblongata + pons (B) in saltresistant (DR) and salt-sensitive (DS) Dahl rats fed either low-salt (LS, $0.3 \% \mathrm{NaCl}$ ) or high-salt (HS, $5.0 \% \mathrm{NaCl}$ ) diet for 2 months from the age of 3 months. Data are mean \pm SEM.
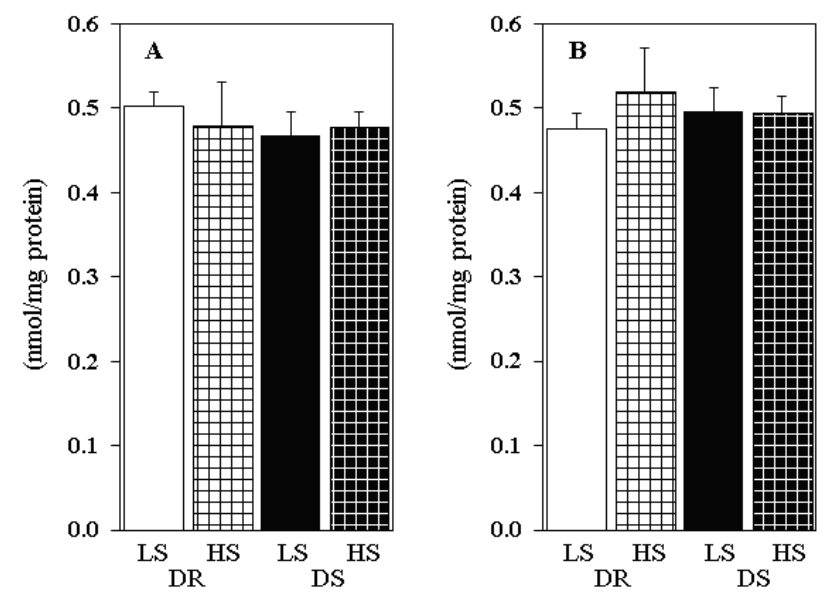

Fig. 2. TBARS concentration in the diencephalon (A) and medulla oblongata + pons (B) in salt-resistant (DR) and saltsensitive (DS) Dahl rats fed either low-salt (LS, $0.3 \% \mathrm{NaCl}$ ) or high-salt $(\mathrm{HS}, 5.0 \% \mathrm{NaCl})$ diet for 2 months from the age of 3 months. Data are mean \pm SEM. 

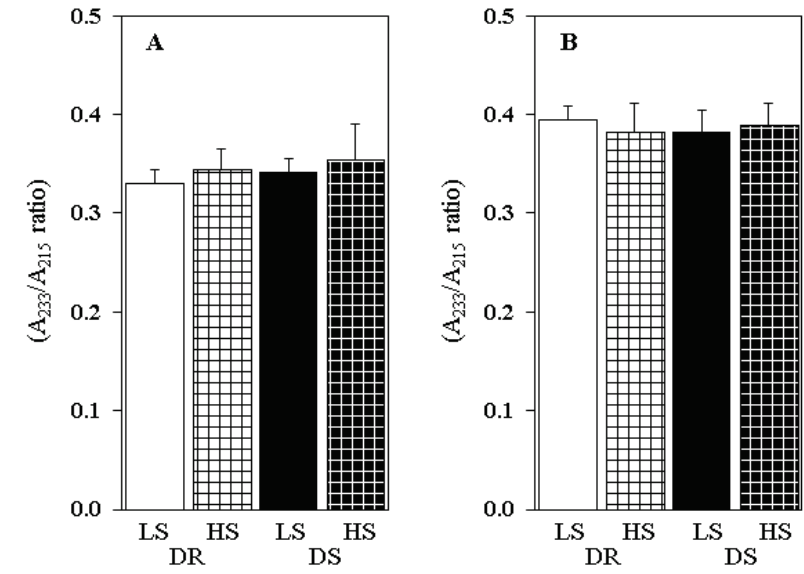

Fig. 3. Oxidative index indicated by absorbance ratio $A_{233} / A_{215}$ in the diencephalon (A) and medulla oblongata + pons (B) in saltresistant (DR) and salt-sensitive (DS) Dahl rats fed either low-salt (LS, $0.3 \% \mathrm{NaCl}$ ) or high-salt (HS, $5.0 \% \mathrm{NaCl}$ ) diet for 2 months from the age of 3 months. Data are mean \pm SEM.

Figure 1 indicates that there were no significant differences (NS) between particular experimental groups in NADPH oxidase-dependent $\mathrm{O}_{2}^{-}$production in either part of the brain (part A: salt intake effect $\mathrm{F}_{1,20}=0.84 \mathrm{NS}$, genotype effect $F_{1,20}=0.58 \mathrm{NS}$ and the interact of both effect $\mathrm{F}_{1,20}=0.93 \mathrm{NS}$; part $\mathrm{B}$ : salt intake effect $\mathrm{F}_{1,20}=$ $0.08 \mathrm{NS}$, genotype effect $\mathrm{F}_{1,20}=1.16 \mathrm{NS}$ and the interact of both effect $F_{1,20}=1.97 \mathrm{NS}$ ). To evaluate the degree of possible brain damage by ROS we measured both TBARS and conjugated dienes (oxidative index) as the indirect markers of lipid peroxidation. We did not observe any difference between DS and DR rats in TBARS contents of selected brain regions and high-salt diet feeding did not change TBARS content in any part of the brain (Fig. 2).
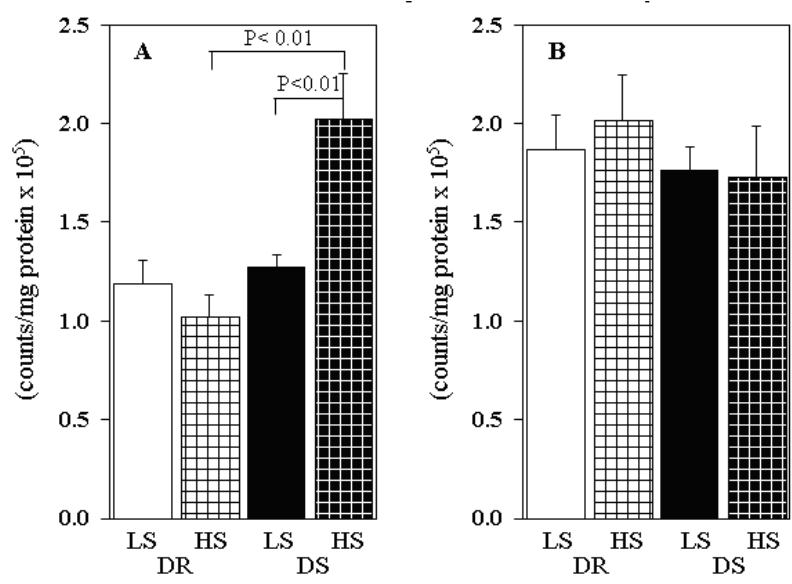

Fig. 4. NADPH oxidase-mediated ROS production in renal medulla (A) and cortex (B) in salt-resistant (DR) and saltsensitive (DS) Dahl rats fed either low-salt (LS, $0.3 \% \mathrm{NaCl}$ ) or high-salt ( $\mathrm{HS}, 5.0 \% \mathrm{NaCl}$ ) diet for 2 months from the age of 3 months. Data are mean \pm SEM.
Furthermore, the determination of this oxidative index confirmed that the development of salt hypertension in DS rats was not accompanied by increased oxidative stress in the brain as compared to DR controls (Fig. 3).
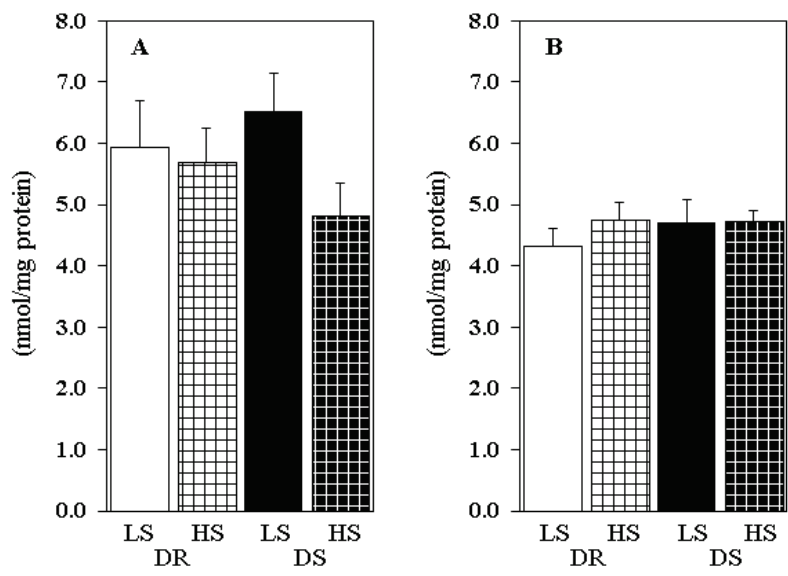

Fig. 5. TBARS concentration in renal medulla (A) and cortex (B) in salt-resistant (DR) and salt-sensitive (DS) Dahl rats fed either low-salt ( $\mathrm{LS}, 0.3 \% \mathrm{NaCl})$ or high-salt ( $\mathrm{HS}, 5.0 \% \mathrm{NaCl})$ diet for 2 months from the age of 3 months. Data are mean \pm SEM.
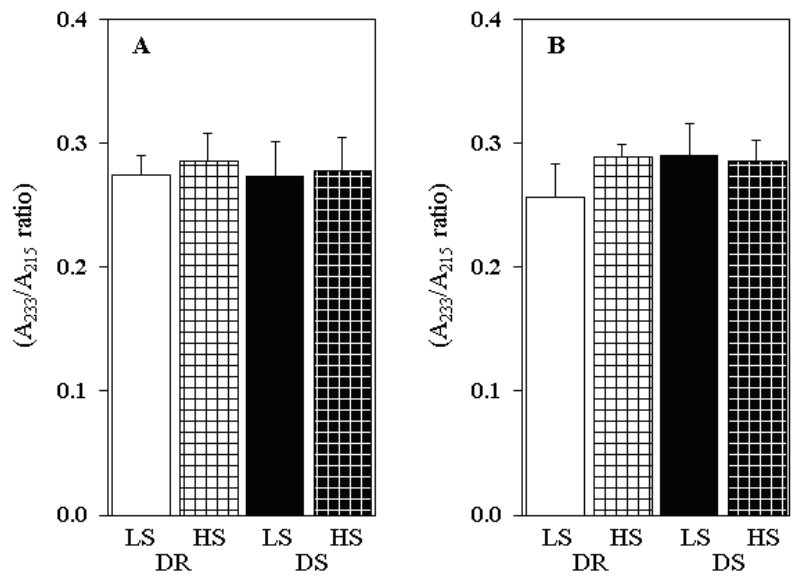

Fig. 6. Oxidative index indicated by the absorbance ratio $A_{233} / A_{215}$ in renal medulla (A) and cortex (B) in salt-resistant (DR) and salt-sensitive (DS) Dahl rats fed either low-salt (LS, $0.3 \% \mathrm{NaCl}$ ) or high-salt (HS, $5.0 \% \mathrm{NaCl}$ ) diet for 2 months from the age of 3 months. Data are mean \pm SEM.

On the contrary, Figure $4 \mathrm{~A}$ shows a major elevation of NADPH oxidase-dependent $\mathrm{O}_{2}^{-}$production in the renal medulla of salt hypertensive DS rats compared to both controls - DR rats fed a high-salt diet and DS rats fed a low-salt diet. Two-way ANOVA revealed salt intake effect $\mathrm{F}_{1,20}=4.83, \mathrm{P}<0.05$; genotype effect $\mathrm{F}_{1,20}=16.63, \mathrm{P}<0.001$ and the interact of both effect $\mathrm{F}_{1,20}=11.92, \mathrm{P}<0.01$. In contrast to renal medulla, there were no significant changes in the renal cortex of 
hypertensive animals (salt intake effect $\mathrm{F}_{1,20}=0.09$, NS; genotype effect $\mathrm{F}_{1,20}=1.03$, NS and the interact of both effect $F_{1,20}=0.22$, NS) (Fig. 4B). Nevertheless, we have not observed any signs of increased lipid peroxidation in the renal medulla or cortex of adult salt hypertensive DS rats (Figs 5 and 6).

\section{Discussion}

The present study provides new data on NADPH oxidase-mediated $\mathrm{O}_{2}^{-}$production and oxidative damage in the brain and kidney of Dahl rats. We examined two parts of brain, which are crucial for BP control. Hypothalamic PVN regulates neuroendocrine and autonomic systems to maintain homeostasis and to respond to stress (Benarroch 2005, Pyner 2009). Brainstem RVLM contains neurons that primary control peripheral sympathetic vasomotor tone and blood pressure (Guyenet 2006, Kumagai et al. 2012).

As far as NADPH oxidase-dependent ROS production in the brain is concerned, we did not find significant strain-dependent or diet-induced differences in either PVN or RVLM containing parts of the brain. The same was true for the levels of end products of lipid peroxidation (TBARS or conjugated dienes) in the brain of Dahl rats. There are few data on the oxidative stress in the brain of Dahl rats. The only relevant study (Fujita et al. 2007) reported that sympathoexcitation due to increased superoxide formation by NADPH oxidase in the hypothalamus was responsible for BP elevation seen in young (immature) salt hypertensive DS rats. Similar sympathoexcitation by brain oxidative stress has been also observed in weanling 3-week-old Sprague Dawley rats subjected to uninephrectomy and high salt intake (Fujita et al. 2012). The dissimilarity of our data and those of Fujita et al. (2007) might be ascribed to the use of Dahl rats of different age and/or colony origin.

On the other hand, we disclosed a major elevation of NADPH oxidase-dependent ROS production in renal medulla of salt hypertensive DS rats. This was in a good agreement with earlier reports on the important role of enhanced superoxide production in renal outer medulla of salt hypertensive DS rats (Taylor et al. 2006, Feng et al. 2012). There are also numerous studies suggesting the role of increased oxidative stress in renal damage occurring in salt hypertensive Dahl animals (Trolliet et al. 2001, Forde et al. 2003, Hisaki et al. 2005, Nagasu et al. 2010, Kim et al. 2012).

Our findings in Dahl rats with salt hypertension induced in adulthood are at variance with the results obtained in adult rats with spontaneous genetic hypertension. Thus, the adult stroke-prone spontaneously hypertensive rats (SHR-SP) had greatly enhanced TBARS levels in the whole brain and in RVLM in comparison with normotensive Wistar-Kyoto (WKY) rats (Kishi et al. 2004). Furthermore, increased $\mathrm{O}_{2}^{-}$levels and reduced manganese superoxide dismutase (Mn-SOD) expression and activity were found in RVLM of adult spontaneously hypertensive rats (SHR) when compared to WKY rats (Tai et al. 2005). The oxidative impairment of mitochondrial electron transport chain complexes in RVLM contributes to the increased sympathetic tone and neurogenic hypertension in SHR (Chan et al. 2009). Nevertheless, we should keep in mind that BP elevation and underlying sympathoexcitation in SHR or SHR-SP appear in the early life, i.e. prior to sexual maturation.

The reasons for age-dependent involvement of oxidative stress in the pathogenesis of salt hypertension as well as for the different ROS production in the brain of young and adult Dahl rats are still unclear. Our earlier experiments (Zicha et al. 2001, Dobešová et al. 2002) revealed that BP reduction following acute tempol administration was greater in young than in adult salt hypertensive DS rats. This acute tempol-induced BP reduction was originally ascribed to the augmentation of NO-dependent vasodilatation (Zicha et al. 2001). Indeed, our studies on vasoactive balance in young and adult Dahl rats disclosed a more pronounced NO deficiency in young than in adult salt hypertensive DS rats (for details see Table 2 in the review by Zicha et al. 2012a). Since the age-dependent difference in acute BP response to tempol was accompanied by augmented contribution of sympathetic nervous system (SNS) to BP maintenance in younger hypertensive group (see Table 2 in Zicha et al. 2012a), a possible involvement of oxidative stress in the enhanced sympathoexcitation can not be excluded. Nevertheless, the above mentioned enhancement of tempol-induced BP changes in young salt hypertensive DS rats can also be ascribed to their more pronounced alterations in baroreflex sensitivity (Nedvídek and Zicha 2000). This might be responsible for a less efficient compensation of tempol-induced BP reduction by the elevation of sympathetic tone in young than in adult animals. On the other hand, Dahl rats with salt hypertension induced in adulthood are characterized by the increased contribution of circulating angiotensin II to BP maintenance (see Table 2 in Zicha et al. 2012a). Since angiotensin II is known to stimulate NADPH oxidase 
activity, this might be a plausible explanation for the enhanced NADPH oxidase activity observed in renal medulla of adult salt hypertensive DS rats. In addition, Vaněčková et al. (2013) reported higher superoxide levels in the aorta of adult salt hypertensive DS rats compared to young ones. Surprisingly, intracellular content of reduced glutathione (GSH) in renal cortex, heart and liver was higher in DS than in DR rats, but it was not influenced by high salt intake in either genotype.

Our chronic experiments in Dahl rats provided several interesting findings concerning age-dependent effects of various antihypertensive interventions. Thus, dietary potassium supplementation attenuated salt hypertension development only in young but not in adult DS animals and this effect was mediated by a reduction of sympathetic vasoconstriction (Zicha et al. 2011). Similarly, dietary calcium supplementation diminished hypertension development in young DS rats, whereas the same high-calcium diet enhanced salt hypertension development in adult DS animals (Kuneš et al. 1988). On the contrary, chronic blockade of endothelin type receptors (Zicha et al. 2012b) or chronic lowering of superoxide levels by oral tempol treatment (Vaněčková et al. 2013) reduced salt hypertension development only in adult but not in young DS rats. It is important to note that in both cases the antihypertensive effects were also due to a decreased contribution of SNS to BP control. This suggests that sympathetic component of salt hypertension can be modulated by several factors the efficiency of which varies according to the age of animals. It would be therefore desirable to know how the above interventions influence ROS formation in the brain or kidney of young and adult DS rats. Even more interesting might be to study the brain ROS formation, sympathetic nerve activity and blood pressure in salt-loaded DS rats subjected to chronic blockade of either angiotensin $\mathrm{AT}_{1}$ or mineralocorticoid receptors in prepuberty because such interventions were reported to attenuate or even prevent salt hypertension development in young Dahl rats (Nakaya et al. 2002, Kawarazaki et al. 2010, Dejima et al. 2011).

In summary, the present study showed neither the increased activity of NADPH oxidase-mediated $\mathrm{O}_{2}{ }^{-}$ production nor the increased levels of TBARS and conjugated dienes in hypothalamus or medulla oblongata of adult salt hypertensive Dahl rats. This is in variance with the results of Fujita et al. (2007), who reported the importance of enhanced oxidative stress in the hypothalamus of young salt hypertensive Dahl rats. This discrepancy further supports considerable age-dependent difference in the participation of reactive oxygen species in the pathogenesis of salt hypertension in immature and adult animals as was earlier suggested by Vaněčková et al. (2013).

\section{Conflict of Interest}

There is no conflict of interest.

\section{Acknowledgements}

The authors would like to thank to Marie Schützová, Alena Charvátová, Zdeňka Kopecká and Iva Nahodilová for their excellent technical assistance. This work was supported by research grant 304/12/0259 (Czech Science Foundation) and RVO: 67985823 (Institute of Physiology).

\section{References}

BARADARAN A, NASRI H, RAFIEIAN-KOPAEI M: Oxidative stress and hypertension: Possibility of hypertension therapy with antioxidants. J Res Med Sci 19: 358-367, 2014.

BAYORH MA, GANAFA AA, SOCCI RR, SILVESTROV N, ABUKHALAF IK: The role of oxidative stress in saltinduced hypertension. Am J Hypertens 17: 31-36, 2004.

BENARROCH EE: Paraventricular nucleus, stress response, and cardiovascular disease. Clin Auton Res 15: 254-263, 2005.

CHAN SH, WU KL, CHANG AY, TAI MH, CHAN JY: Oxidative impairment of mitochondrial electron transport chain complexes in rostral ventrolateral medulla contributes to neurogenic hypertension. Hypertension 53: 217-227, 2009.

DAHL LK, HEINE M, TASSINARI L: Effects of chronic excess salt ingestion. Evidence that genetic factors play an important role in susceptibility to experimental hypertension. $J$ Exp Med 115: 1173-1190, 1962. 
DEJIMA T, TAMURA K, WAKUI H, MAEDA A, OHSAWA M, KANAOKA T, HAKU S, KENGO A, MASUDA S, SHIGENAGA A, AZUMA K, MATSUDA M, YABANA M, HIROSE T, UCHINO K, KIMURA K, NAGASHIMA Y, UMEMURA S: Prepubertal angiotensin blockade exerts long-term therapeutic effect through sustained ATRAP activation in salt-sensitive hypertensive rats. J Hypertens 29: 1919-1929, 2011.

DOBEŠOVÁ Z, KUNEŠ J, ZICHA J: The altered balance between sympathetic nervous system and nitric oxide in salt hypertensive Dahl rats: ontogenetic and $\mathrm{F}_{2}$ hybrid studies. J Hypertens 20: 945-955, 2002.

ELLMAN GL: Tissue sulfhydryl groups. Arch Biochem Biophys 82: 70-77, 1959.

FENG D, YANG C, GEURTS AM, KURTH T, LIANG M, LAZAR J, MATTSON DL, O'CONNOR PM, COWLEY AW JR: Increased expression of $\mathrm{NAD}(\mathrm{P}) \mathrm{H}$ oxidase subunit p67(phox) in the renal medulla contributes to excess oxidative stress and salt-sensitive hypertension. Cell Metab 15: 201-208, 2012.

FORDE P, SCRIBNER AW, DIAL R, LOSCALZO J, TROLLIET MR: Prevention of hypertension and renal dysfunction in Dahl rats by alpha-tocopherol. J Cardiovasc Pharmacol 42: 82-88, 2003.

FUJITA M, ANDO K, NAGAE A, FUJITA T: Sympathoexcitation by oxidative stress in the brain mediates arterial pressure elevation in salt-sensitive hypertension. Hypertension 50: 360-367, 2007.

FUJITA M, ANDO K, KAWARAZAKI H, KAWARASAKI C, MURAOKA K, OHTSU H, SHIMIZU H, FUJTA T: Sympathoexcitation by brain oxidative stress mediates arterial pressure elevation in salt-induced chronic kidney disease. Hypertension 59: 105-112, 2012.

GABOR A, LEENEN FH: Central neuromodulatory pathways regulating sympathetic activity in hypertension. $J$ Appl Physiol 113: 1294-1303, 2012.

GUO P, NISHIYAMA A, RAHMAN M, NAGAI Y, NOMA T, NAMBA T, ISHIZAWA M, MURAKAMI K, MIYATAKE A, KIMURA S, MIZUSHIGE K, ABE Y, OHMORI K, KOHNO M: Contribution of reactive oxygen species to the pathogenesis of left ventricular failure in Dahl salt-sensitive hypertensive rats: effects of angiotensin II blockade. J Hypertens 24: 1097-1104, 2006.

GUYENET P: The sympathetic control of blood pressure. Nat Rev Neurosci 7: 335-346, 2006.

HIROOKA Y: Oxidative stress in the cardiovascular center has a pivotal role in the sympathetic activation in hypertension. Hypertens Res 34: 407-412, 2011.

HISAKI R, FUJITA H, SAITO F, KUSHIRO T: Tempol attenuates the development of hypertensive renal injury in Dahl salt-sensitive rats. Am J Hypertens 18: 707-713, 2005.

KAPLÁN P, DOVAL M, MAJEROVÁ Z, LEHOTSKÝ J, RACAY P: Iron-induced lipid peroxidation and protein modification in endoplasmic reticulum membranes. Protection by stobadine. Int $J$ Biochem Cell Biol 32: 539-547, 2000.

KAWARAZAKI H, ANDO K, NAGAE A, FUJITA M, MATSUI H, FUJITA T: Mineralocorticoid receptor activation contributes to salt-induced hypertension and renal injury in prepubertal Dahl salt-sensitive rats. Nephrol Dial Transplant 25: 2879-2889, 2010.

KIM YH, HWANG JH, NOH JR, GANG GT, TADI S, YIM YH, JEOUNG NH, KWAK TH, LEE SH, KWEON GR, KIM JM, SHONG M, LEE IK, LEE CH: Prevention of salt-induced renal injury by activation of NAD(P)H:quinone oxidoreductase 1, associated with NADPH oxidase. Free Radic Biol Med 52: 880-888, 2012.

KISHI T, HIROOKA Y, KIMURA Y, ITO K, SHIMOKAWA H, TAKESHITA A: Increased reactive oxygen species in rostral ventrolateral medulla contribute to neural mechanisms of hypertension in stroke-prone spontaneously hypertensive rats. Circulation 109: 2357-2362, 2004.

KLEIN RA: The detection of oxidation in liposome preparations. Biochim Biophys Acta 210: 486-489, 1970.

KUMAGAI H, OSHIMA N, MATSUURA T, IIGAYA K, IMAI M, ONIMARU H, SAKATA K, OSAKA M, ONAMI T, TAKIMOTO C, KAMAYACHI T, ITOH H, SARUTA T: Importance of rostral ventrolateral medulla neurons in determining efferent sympathetic nerve activity and blood pressure. Hypertens Res 35: 132-141, 2012.

KUNEŠ J, ZICHA J, HAMET P: Effects of dietary calcium on the development of salt hypertension in young and adult Dahl rats. J Hypertens 6 (Suppl 4): S225-S227, 1988.

LASSÈGUE B, GRIENDLING KK: Reactive oxygen species in hypertension; An update. Am J Hypertens 17: 852-860, 2004. 
LOWRY OH, ROSEBROUGH NJ, FARR AL, RANDALL RJ: Protein measurement with the Folin phenol reagent. J Biol Chem 193: 265-275, 1951.

MANNING RD JR, TIAN N, MENG S: Oxidative stress and antioxidant treatment in hypertension and the associated renal damage. Am J Nephrol 25: 311-317, 2005.

MATSUI H, SHIMOSAWA T, UETAKE Y, WANG H, OGURA S, KANEKO T, LIU J, ANDO K, FUJITA T: Protective effect of potassium against the hypertensive cardiac dysfunction: association with reactive oxygen species reduction. Hypertension 48: 225-231, 2006.

MENG S, CASON GW, GANNON AW, RACUSEN LC, MANNING RD JR: Oxidative stress in Dahl salt-sensitive hypertension. Hypertension 41: 1346-1352, 2003.

NAGASU H, SATOH M, KUWABARA A, YORIMITSU D, SAKUTA T, TOMITA N, KASHIHARA N: Renal denervation reduces glomerular injury by suppressing NAD(P)H oxidase activity in Dahl salt-sensitive rats. Nephrol Dial Transplant 25: 2889-2898, 2010.

NAKAYA H, SASAMURA H, MIFUNE M, SHIMIZU-HIROTA R, KURODA M, HAYASHI M, SARUTA T: Prepubertal treatment with angiotensin receptor blocker causes partial attenuation of hypertension and renal damage in adult Dahl salt-sensitive rats. Nephron 91: 710-718, 2002.

NEDVÍDEK J, ZICHA J: Baroreflex control of heart rate in young and adult salt hypertensive inbred Dahl rats. Physiol Res 49: 323-330, 2000.

NISHIYAMA A, YOSHIZUMI M, HITOMI H, KAGAMI S, KONDO S, MIYATAKE A, FUKUNAGA M, TAMAKI T, KIYOMOTO H, KOHNO M, SHOKOJI T, KIMURA S, ABE Y: The SOD mimetic tempol ameliorates glomerular injury and reduces mitogen-activated protein kinase activity in Dahl salt-sensitive rats. $J$ Am Soc Nephrol 15: 306-315, 2004.

OHKAWA H, OHISHI N, YAGI K: Assay for lipid peroxides in animal tissues by thiobarbituric acid reaction. Anal Biochem 95: 351-358, 1979.

PARIK T, ALLIKMETS K, TEESALU R, ZILMER M: Evidence for oxidative stress in essential hypertension: perspective for antioxidant therapy. J Cardiovasc Risk 3: 49-54, 1996.

PAXINOS G, WATSON C: The Rat Brain in Stereotaxic Coordinates. (Fifth edition), Elsevier Academic Press, Amsterdam, 2005.

PYNER S: Neurochemistry of the paraventricular nucleus of the hypothalamus: implications for cardiovascular regulation. J Chem Neuroanat 38: 197-208, 2009.

RODRIGO R, GONZÁLEZ J, PAOLETTO F: The role of oxidative stress in the pathophysiology of hypertension. Hypertens Res 34: 431-440, 2011.

SWEI A, LACY F, DELANO FA, SCHMID-SCHÖNBEIN GW: Oxidative stress in the Dahl hypertensive rat. Hypertension 30: 1628-1633, 1997.

SWEI A, LACY F, DELANO FA, PARKS DA, SCHMID-SCHÖNBEIN GW: A mechanism of oxygen free radical production in the Dahl hypertensive rat. Microcirculation 6: 179-187, 1999.

TAI MH, WANG LL, WU KL, CHAN JY: Increased superoxide anion in rostral ventrolateral medulla contributes to hypertension in spontaneously hypertensive rats via interactions with nitric oxide. Free Radic Biol Med 38: 450-462, 2005.

TAYLOR NE, COWLEY AW JR: Effect of renal medullary $\mathrm{H}_{2} \mathrm{O}_{2}$ on salt-induced hypertension and renal injury. $A m \mathrm{~J}$ Physiol Regul Integr Comp Physiol 289: R1573-R1579, 2005.

TAYLOR NE, GLOCKA P, LIANG M, COWLEY AW JR: NADPH oxidase in the renal medulla causes oxidative stress and contributes to salt-sensitive hypertension in Dahl S rats. Hypertension 47: 692-698, 2006.

TOJO A, ONOZATO ML, KOBAYASHI N, GOTO A, MATSUOKA H, FUJITA T: Angiotensin II and oxidative stress in Dahl Salt-sensitive rat with heart failure. Hypertension 40: 834-839, 2002.

TROLLIET MR, RUDD MA, LOSCALZO J: Oxidative stress and renal dysfunction in salt-sensitive hypertension. Kidney Blood Press Res 24: 116-123, 2001.

TSUTSUI H, IDE T, HAYASHIDANI S, KINUGAWA S, SUEMATSU N, UTSUMI H, TAKESHITA A: Effects of ACE inhibition on left ventricular failure and oxidative stress in Dahl salt-sensitive rats. $J$ Cardiovasc Pharmacol 37: 725-733, 2001. 
VANĚČKOVÁ I, VOKURKOVÁ M, RAUCHOVÁ H, DOBEŠOVÁ Z, PECHÁŇOVÁ O, KUNEŠ J, VORLÍČEK J, ZICHA J: Chronic antioxidant therapy lowers blood pressure in adult but not in young Dahl salt hypertensive rats: the role of sympathetic nervous system. Acta Physiol (Oxf) 208: 340-349, 2013.

ZHANG L, FUJII S, IGARASHI J, KOSAKA H: Effects of thiol antioxidant on reduced nicotinamide adenine dinucleotide phosphate oxidase in hypertensive Dahl salt-sensitive rats. Free Radic Biol Med 37: 1813-1820, 2004.

ZICHA J, KUNEŠ J: Ontogenetic aspects of hypertension development: analysis in the rat. Physiol Rev 79: 1227-1282, 1999.

ZICHA J, KUNEŠ J, JELÍNEK J: Experimental hypertension in young and adult animals. Hypertension 8: 1096-1104, 1986.

ZICHA J, DOBEŠOVÁ Z, KUNEŠ J: Relative deficiency of nitric oxide-dependent vasodilatation in salt-hypertensive Dahl rats: the possible role of superoxide anions. J Hypertens 19: 247-254, 2001.

ZICHA J, DOBEŠOVÁ Z, BEHULIAK M, KUNEŠ J, VANĚČKOVÁ I: Preventive dietary potassium supplementation in young salt-sensitive Dahl rats attenuates development of salt hypertension by decreasing sympathetic vasoconstriction. Acta Physiol (Oxf) 202: 29-38, 2011.

ZICHA J, DOBEŠOVÁ Z, VOKURKOVÁ M, RAUCHOVÁ H, HOJNÁ S, KADLECOVÁ M, BEHULIAK M, VANĚČKOVÁ I, KUNEŠ J: Age-dependent salt hypertension in Dahl rats: fifty years of research. Physiol Res 61 (Suppl 1): S35-S87, 2012a.

ZICHA J, DOBEŠOVÁ Z, KUNEŠ J, VANĚČKOVÁ I: chronic endothelin a receptor blockade attenuates contribution of sympathetic nervous system to salt hypertension development in adult but not in young Dahl rats. Acta Physiol (Oxf) 205: 124-132, 2012b. 